\title{
PENGARUH KUALITAS KERJA DAN KOMPENSASI TERHADAP PRESTASI KERJA KARYAWAN PADA PT. LARAS INTER NUSA (LIN) SIDODADI KECAMATAN KINALI PASAMAN BARAT
}

\author{
Nusra Fernando, Febsri Susanti \\ Sekolah Tinggi Ilmu Ekonomi KBP \\ nusrafernando5003@gmail.com \\ febsrisusanti@akbpstie.ac.id
}

\begin{abstract}
ABTRACT
This study aims to determine and analyze how much influence the Quality of Work (X1), Compensation (X2), and Employee Work Achievement (Y) at PT. Laras Inter Nusa (LIN) Sidodadi Kinali District Pasaman Barat. by using data collection methods in the form of questionnaires as many as 52 respondents. In the analysis of data using the test of validity, reliability, and classical assumption test that is normality, multicollinearity, heteroscedasticity, and autocorrelation. The analysis method used is multiple linear regression analysis. Whereas for testing hypotheses are F test, T test, determinant coefficient R2 using SPSS tools. The results of the study show that the variable Work Quality has an effect on Employee Performance (Y) at PT. Laras Inter Nusa (LIN) Sidodadi District Kinali Pasaman Barat, Compensation variable does not affect Employee Work Performance (Y) at PT. Laras Inter Nusa (LIN) Sidodadi Kinali District Pasaman Barat.
\end{abstract}

Keywords: Work Quality, Compensation, Employee Performance

\section{PENDAHULUAN}

Karyawan dengan perusahaan dua hal yang tidak dapat dipisahkan karena Dengan semakin berkembangnya kedudukan Karyawan yang ada dalam perusahaan, sebaiknya perusahaan memberikanjaminan yang memadai untuk mendukung kinerja karyawan. Dimaksudkan agar karyawan dapat memberikan pengaruh yang besar kepada perusahaan dengan memanfaatkan skill yang mereka miliki untuk dapat berpacu dalam kompetisi dengan memberikan prestasi kepada perusahaan demi kelancaran proses produksi dan jalannya perusahaan. Melihatbegitu bergunanya karyawan didalam perusahaan, sebaiknya perusahaan memberi perhatian yang lebih kepada karyawan.

Prestasi Kerja Menurut (Gomez, 2009) adalah untuk meningkatkan keterampilan kerja, termasuk melakukan bimbingan pada pekerja dan meberlakukan training bagi karyawan. Karyawan yang berprestasi adalah bagian terpenting dalam perusahaan. Dalam hal ini diperlukan pengetahuan untuk memotivasi karyawan agar mau bekerja dengan dedikasi yang tinggi. Untuk mewujudkan tujuan tersebut, seharusnya karyawan harus memiliki potensi yang profesional supaya karyawan memiliki respons dengan kebutuhan perusahaan. 
Kompensasi juga sagat berperan penting dalam kemajuan karyawan, karna kompensasi juga dipengaruhi oeh kualitas yang baik dan kuanlitas yang baik akan menimbulkan prestasi yang baik pula, seseorang karyawan harus bisa memberikan prestasi kerja yang lebih baik. Menurut (Rivai\&Sagala, 2003) menyatakan bahwa: Kompensasi sebagai pengganti Kontribusi jasa pada perusahaan. Pemberian kompensasi berhubungan erat dengan pelaksanaan fungsi MSDM yang berhubungan dengan semua jenis pemberian individual sebagai pertukaran dalam melakukan tugas keorganisasian.

PT. Laras Inter Nusa (LIN) kecamatan Kinali Kabupaten Pasaman Barat, merupakan salah satu perushaan yang bergerak dibidang pengelolaan barang mentah yang beralokasi di Kejorongan VI Koto Selatan, dimana perusahaan ini menghasilkan buah sawit, PT. Laras Inter Nusa yang di singkat dengan (PT. LIN)Kecamatan Kinali Kabupaten Pasaman Barat,merupakan sebuah perusahaan yang bergerak di bidang perkebunan kelapa sawit. Dengan lahan atau lingkungan perusahaan yang luas sehingga membutuhkan sumber daya yang mampu menampung semua pekerjaan di dalam perusahaan, serta sumber daya yang mampu berproduktivitas dengan baik. Sebagai perusahaan besar PT.Laras Inter Nusa (LIN)Kecamatan Kinali Kabupaten Pasaman Barat perlu memperhatikan berbagai hal pada karyawan yang bisa meningkatkan prestasi kerja.

Untuk menciptakan perkembangan yang tinggi tidak hanya dapat dicapai dengan modal yang besar, tetapi perusahaan seperti PT. Laras Inter Nusa(LIN)Kecamatan Kinali Kabupaten Pasaman Barat juga harus memiliki tenaga kerja atau karyawan yang mempunyai skill atau keahlian tentang perkebunan sehingga bisa berproduktivitas tinggi.Dengan banyak perusahaan yang bergerak dalam usaha yang sama, diharapkan PT. Laras Inter Nusa (LIN) Kecamatan Kinali Kabupaten Pasaman Barat mampu memperhatikan Kualitas kerja dan Kompensasi Kerja terhadap prestasi kerja karyawan sehingga bisa bersaing dengan perusahaan lainnya.

Hal ini bisa terlihat dengan banyak karyawan padaPT.Laras Inter Nusa(LIN)Kecamatan Kinali Kabupaten Pasaman Barat, dimana karyawan dalam bekerja harus sesuai dengan program kerja yang ditetapkan oleh perusahaan untuk mencapai visi, misi, dan tujuan. Sehubungan dengan fungsi manajemen manapun, aktivitas manajemen sumber daya manusia harus dikembangkan, dievaluasi, dan diubah apabila perlu, sehingga mereka dapat memberikan kontribusi pada pekerjaan mereka.

Martoyo (1996:105) mendefinisikan Prestasi Kerja sebagai hasil kerja yang dicapai oleh seseorang dalam melakukan tugas-tugasnya yang dibebankan kepadanya berdasarkan kemampuan, usaha, kecakapan, pengalaman, dan kesungguhan.Berdasarkan pengertian yang dikemukakan diatas dapt ditarik kesimpulan bahwa Prestasi Kerja adalah suatu hasil kerja yang dapat dicapai atau diperoleh dari seseorang berdasarkan kreteria yang telah ditetapkan sesuaikemampuan yang dimiliki untuk mendpat membantu mencapai tujuan perusahaan.

Kualitas kerja yang mengacu pada kualitas sumber daya manusia seperti pengetahuan keterampilan dan kemampuan yang dimiliki seseorang karyawan (Wilson\&Heyel, 1987). Kualitas kerja adalah salah satu unsur yang dievaluasi dalam menilai kinerja karyawan.Selain prilaku seperti didikasi kesetiaan kepemimpinan kejujuran kerja sama loyalitas dan partisipasi karyawan. 
H1 : Diduga adanya pengaruh positif dan signifikan antara Kualitas Kerja terhadap Prestsi kerja Karyawan pada PT. Laras Inter Nusa (LIN) SidodadiKecamatan Kinali Kabupaten Pasaman Barat.

Pemberian kompensasi merupakan fungsi strategik sumber daya manusia yang mempunyaiimbas singnifikan atas fungsi-fungsi sumber daya manusia lainnya (Martinus, 2016). Salah satu cara manajemen untuk meningkatkan prestasi kerja, memotivasi dan meningkatkan kinerja para karyawan adalah melalui kompensasi

H2 : Diduga adanya pengaruh positif dan signifikan antara Kompensasi terhadap Prestsi kerja Karyawan padaPT. Laras Inter Nusa (LIN) Sidodadi Kecamatan KinaliKabupaten Pasaman Barat

\section{METODE PENELITIAN}

Jenis Penelitian ini adalah penelitian kuantitatif karena berlandaskan pada filsafat positivisme. Penelitian ini disebut dengan data kuantitatif karena berupa angka-angka dan penelitian ini menggunakan statistic (Sugiyono, 2017).Penelitian ini untuk melihat sejauh mana pengaruh Kualitas kerja dan Kompensasi Terhadap Prestasi Kerja Karyawan pada PT. Laras Inter Nusa (LIN) Sidodadi Kecamatan Kinali Kabupaten Pasaman Barat.

Setelah melihat pendahuluan dan kajian literatur dari penelitian ini dan untuk memperoleh hasil yang sesuai dengan yang diharapkan maka penulis memilih tempat di PT.Laras Inter Nusa (LIN) Sidodadi Kecamatan Kinali Kabupaten Pasaman Barat.

Dalam penelitian ini, yang menjadi populasi adalah seluruh karyawan yang ada di PT. Laras Inter Nusa (LIN) Sidodadi Kecamatan Kinali Kabupaten Pasaman Barat yang berjumlah 60 Karyawan.Metode penetapan sampel dilakukan dengan cara Probalitiy Sampling. Probalitiy Sampling yaitu teknik pengambilan sampel yang memberikan peluang yang sama bagi semua unsur (anggota) populasi untuk dipilih menjadi anggota sampel, (Sugiyono, 2008).

\section{Teknik Pengumpula Data}

Beberapa sumber data yang digunakan oleh penulis dalam pengumpulan data didalam penelitian ini adalah: untuk memperoleh data yang diperlukan dalam penelitian ini maka penulis menggunakan teknik pengumpulan data sebagai berikut :

\section{Kuesioner atau Angket}

Metode yang digunakan untuk mendapatkan data primer berupa daftar pernyataan yang sistematis kepada karyawan dengan menyiapkan pernyataan-pernyataanyang berhubungan denganpengaruh Kualitas kerja dan Kompensasi terhadap Prestasi kerja karyawan pada PT. Laras Inter Nusa(LIN)SidodadiKecamatan Kinali Kabupaten Pasaman Barat. Kuesioner ini berpedoman pada skala likert.

\section{Observasi}

Teknik ini digunakan untuk memperoleh data secara langsung kelapangan.

\section{Field Research (Wawancara)}

Metodeyang digunakan dengan cara melakukan tanya jawab langsung dengan karyawan pada PT. Laras Inter Nusa (LIN) Sidodadi Kecamatan Kinali Kabupaten Pasaman Barat. 


\section{Defenisi Operasional Variabel}

Tabel 1

Defenisi Operasional Variabel

\begin{tabular}{|c|c|c|c|c|}
\hline Variabel & Definisi & Indikator & Sumber & $\begin{array}{lll}\text { Alat } & \text { Ukur } & \text { Skala } \\
\text { Likert } & & \end{array}$ \\
\hline $\begin{array}{l}\text { Prestasi } \\
\text { Kerja } \\
\text { (Y) }\end{array}$ & $\begin{array}{l}\text { Prestasi } \\
\text { merupakan hasil kerja } \\
\text { yang dicapai oleh } \\
\text { seseorang sesua dengan } \\
\text { kemampuan yang ia } \\
\text { miliki }\end{array}$ & $\begin{array}{ll}\text { 1. } & \text { Kualitas kerja. } \\
\text { 2. } & \text { Kuantitas kerja. } \\
\text { 3. } & \text { Kerja sama. } \\
\text { 4. } & \text { Tanggung Jawab. }\end{array}$ & $\begin{array}{l}\text { Mangkunegara } \\
(2002: 67)\end{array}$ & $\begin{array}{l}\text { Skala Likert } \\
\text { 1. } \quad \text { Sangat setuju } \\
\text { 2. } \quad \text { Setuju } \\
\text { 3. } \\
\text { 4. } \\
\text { 5. } \\
\text { Tidak setuju } \\
\text { Sangat tidak setuju }\end{array}$ \\
\hline $\begin{array}{l}\text { Kualitas } \\
\text { Kerja } \\
\text { (X1) }\end{array}$ & $\begin{array}{lr}\text { Hasil kerja } & \text { karyawan } \\
\text { yang } & \text { meliputi } \\
\text { kesesuaian,kerapian dan } \\
\text { kelengkapan } & \text { untuk } \\
\text { mencapai } & \text { suatu } \\
\text { keberhasilan } & \end{array}$ & $\begin{array}{l}\text { 1. Hasil kerja yang } \\
\text { diperoleh. } \\
\text { 2. Kesesuaian hasil } \\
\text { kerja dengan } \\
\text { tujuan organisasi. } \\
\text { 3. Manfaat hasil } \\
\text { kerja. }\end{array}$ & $\begin{array}{l}\text { (Wilson\&Heyel, } \\
\text { 1987) }\end{array}$ & $\begin{array}{l}\text { Skala Likert } \\
\text { 1. } \\
\text { 2. Sangat setuju } \\
\text { 3. } \\
\text { 4. Netuju } \\
\text { 5. } \\
\text { Tidak setuju } \\
\text { Sangat tidak setuju }\end{array}$ \\
\hline $\begin{array}{l}\text { Kompens } \\
\text { asi(X2) }\end{array}$ & $\begin{array}{l}\text { Kompensasi adalah } \\
\text { imbalan atau tunjangan } \\
\text { yang diberikan oelh } \\
\text { karyawan sebagai hasil } \\
\text { kontribusi terhadap } \\
\text { perusahaan }\end{array}$ & $\begin{array}{ll}\text { 1. } & \text { Upah dan Gaji } \\
\text { 2. Insentif } \\
\text { 3. Tunjangan } \\
\text { 4. fasilitas }\end{array}$ & $\begin{array}{l}\text { (Simamora, } \\
\text { 2004) }\end{array}$ & \begin{tabular}{|ll}
\multicolumn{2}{|l}{ Skala Likert } \\
1. & Sangat setuju \\
2. & Setuju \\
3. & Netral \\
4. & Tidak setuju \\
5. & Sangat tidak setuju
\end{tabular} \\
\hline
\end{tabular}

\section{Uji Instrumen Penelitian}

\section{Uji Validitas}

Sebelum instrumen penelitian digunakan untuk mengumpulkan data perlu dilakukan pengujian validitas. Hal ini digunakan untuk mendapatkan data yang valid dari instrumen yang valid. Menurut (Sugiyono, 2012)hasil penelitian yang valid bila terdapat kesamaan anatara data yang terkumpul dengan data yang sesungguhnya terjadi pada objek yang diteliti". Pengujian instrumen dalam penelitian ini dilakukan dengan korelasi bivariate antara masing-masing skor indikator dengan total skor konstruk.

\section{Uji Reliabilitas}

Menurut (Sugiyono, 2012)"instrumen yang reliabel adalah instrumen yang bila digunakan beberapa kali untuk mengukur obyek yang sama, akan menghasilkan data yang sama." Setelah instrumen di uji validitasnya maka langkah selanjutnya yaitu menguji reliabilitas. Adapun menurut Imam Ghozali pengukuran reliabilitas dapat dilakukan dengan dua cara yaitu:

a. Repeated Measureatau pengukuran ulang: disini seseorang akan disodori pertanyaan yang sama pada waktu yang berbeda, dan kemudian dilihat apakah ia tetap konsisten dengan jawabannya.

b. One Shot atau pengukuran sekali saja: disini pengukurannya hanya sekali dan kemudian hasilnya dibandingkan dengan pertanyaan lain atau pengukur korelasi antar jawaban pertanyaan. SPSS memberikan fasilitas untuk mengukur reliabilitas dengan uji statistic Cronbach Aplha ( $\alpha$ ).(Ghozali, 2011) Penelitian yang akan dilakukan menggunakan pengukuran reliabilitas cara kedua yaitu One Shot atau pengukuran sekali saja. Pengukuran reliabilitas dalam penelitian ini dibantu dengan SPSS untuk uji statistic Cronbach Aplha $(\alpha)$.Hasil dari uji statistic Cronbach Aplha $(\alpha)$ akan menentukan instrument yang digunakan dalam penelitian ini reliable digunakan atau tidak. 


\section{Teknik Analisis Data}

Analisis data adalah pengolahan data yang diperoleh menggunakan rumus atau aturan-aturan yang ada sesuai dengan pendekatan peneliti. Arikunto (2002:240).

\section{UjiAsumsiKlasik}

\section{UjiNormalitas}

Bertujuan untuk menguji apakah dalam model regresi variabel pengganggu atau residual memiliki distribusi normal atau tidak. Modal regresi yang baik adalah memiliki distribusi data normal atau mendekati normal. Salah satu cara termudah untuk melihat normalitas residual adalah dengan melihat grafik histogram uji normalitas. (Ghozali, 2005) berpedoman pada uji Kolmogorov Smirnov yaitu :

a. Jika nilai signifikansi $<0,05$ (taraf kepercayaan $95 \%$ ) distribusi adalah tidak normal.

b. Jika nilai signifikansi > 0,05 (taraf kepercayaan $95 \%$ ) distribusi adalah normal.

\section{Uji Linearitas}

Menurut (Sudjana, 2003), dengan menggunakan diagram pencar maka dapat dilihat apakah terdapat suatu hubungan yang berarti antara kedua variabel tersebut. Jika terjadi gejala bahwa letak titik-titik (data) itu ada pada atau menyebar sekitar garis lurus diagonalnya, maka cukup menjadi alasan bahwa antara variabel-variabel tersebut ada hubungan linear. Dan jika data menyebar jauh dari diagonal danatau tidak mengikuti arah garis diagonal,maka dapat diduga terdapat hubungan non-linear.

Uji linearitas digunakan untuk melihat apakah spesifikasi model yang digunakan sudah benar atau tidak. Untuk menentukan apakah fungsi persaman regresi yang digunakan berbentuk linear,maka dapat dilihat dari P. Plot. Apakah titik-titik distribusi mengikuti garis linear, maka model regresi dapat dinyatakan linear. Dalam penelitian ini,untuk uji linearitas dipergunakan Grafik P-P. Plot.

\section{Uji Multikolinieritas}

Uji multikolinearitas bertujuan untuk menguji apakah model regresi ditemukan adanya korelasi antar variabel bebas. Model regresi yang baik seharusnya tidak terjadi korelasi di antara variabel bebas. Menurut (Martinus, 2016) ketentuan dalam pengujian multikolonieritas adalah:

a. Jika nilai tolerance $<0,10$ dan VIF $>10$, maka terdapat korelasiyang terlalu besar di antara salah satu variabel bebas dengan variabel-variabel bebas yang lain (terjadi multikolonieritas).

b. Jika nilai tolerance $>0,10$ dan VIF $<10$, maka tidak terjadi multikolonieritas.

\section{Uji Heteroskedastisitas}

Menurut Santoso (2007) uji heteroskedastisitas bertujuan untuk menguji apakah dalam suatu model regresi terjadi ketidaksamaan variance dari residual satu pengamatan ke pengamatan yang lain.Salah satu cara untuk mendeteksi terjadi tidaknya heteroskedastisitas adalah dengan melihat Grafik Plot Regresi antara nilai Prediksi Variabel Terikat atau Dependent (ZPRED) dengan residualnya (SRESID), yaitu dengan melihat ada tidaknya pola tertentu pada grafik scatter plot antara SRESID dan ZPRED, dimana sumbu Y adalah Y yang telah diprediksi dan sumbu $X$ adalah residual. 
Dasar Analisis :

a. Jika ada pola tertentu, seperti titik-titik yang membentuk pola tertentu yang teratur (Bergelombang, melebar kemudian menyempit), mengindikasikan telah terjadinya heteroskedastisita

b. Jika tidak ada pola yang jelas, serta titik-titik menyebar diatas dan dibawah angka 0 (Nol) pada sumbu Y, maka tidak terjadi heteroskedastisitas.

\section{HASIL DAN PEMBAHASAN \\ Uji Validitas dan Reliabilitas \\ 1. Uji Validitas \\ a. KualitasKerja}

Tabel 2

HasilUjiValiditasKualitasKerja

\begin{tabular}{|c|c|c|c|}
\hline Variabel & No. Butir & $\begin{array}{c}\text { Corrected item - } \\
\text { Total } \\
\text { Correlatioan } \\
\end{array}$ & Keterangan \\
\hline \multirow{5}{*}{ KualitasKerja } & 1 & 0,371 & Valid \\
\hline & 2 & 0,486 & Valid \\
\hline & 3 & 0,417 & Valid \\
\hline & 4 & 0,649 & Valid \\
\hline & 5 & 0,398 & Valid \\
\hline Padc & di & \multicolumn{2}{|c|}{ atasmenunjukkanbahwadari } \\
\hline
\end{tabular}

b.Kompensasi

Tabel 3

HasilUjiValiditasKompensasi

\begin{tabular}{cccc}
\hline Variabel & No Butir & $\begin{array}{c}\text { Corrected item } \\
\text { - Total } \\
\text { Correlatioan }\end{array}$ & Keterangan \\
\hline Kompensasi & 1 & 0,490 & Valid \\
& 2 & 0,654 & Valid \\
& 4 & 0,749 & Valid \\
& 5 & 0,323 & Valid \\
\hline
\end{tabular}

Berdasarkan table diatas menunjukkan bahwa 5 butir pertanyaan darivariabel kompensasi dinyatakan valid karena nilai Corrected item Total Correlatioan lebih besar dari nilai 0,300 sehingga dapat digunakan untuk penelitian lebih lanjut. 
Tabel 4

HasilUjiValiditas VariabelPrestasiKerja

\begin{tabular}{cccc}
\hline Variabel & No Butir & $\begin{array}{l}\text { Corrected item } \\
\text { - Total } \\
\text { Correlatioan }\end{array}$ & $\begin{array}{l}\text { Keteran } \\
\text { gan }\end{array}$ \\
\hline \multirow{2}{*}{ PrestasiKerja } & 1 & 0,406 & Valid \\
& 3 & 0,515 & Valid \\
& 4 & 0,626 & Valid \\
& 5 & 0,504 & Valid \\
\hline
\end{tabular}

Berdasarkan table diatas menunjukkan bahwa 5 butir pernyataan dari variable pretasi kerja dinyatakan valid karena nilai Corrected item - Total Correlatioan lebih besar dari nilai 0,300 sehingga dapat digunakan untuk penelitian lebih lanjut.

\section{Uji Reliabilitas}

\section{Tabel 5}

HasilUjiReliabilitas

\begin{tabular}{lrrll}
\hline Variabel & $\begin{array}{l}\text { JumlahButir } \\
\text { Pertanyaan }\end{array}$ & $\begin{array}{l}\text { Cronbach's } \\
\text { Alpha }\end{array}$ & $\begin{array}{l}\text { Rule of } \\
\text { thumb }\end{array}$ & Keputusan \\
\hline Kualitaskerja & 5 butir & 0,704 & 0,60 & Reliable \\
Kompensasi & 5 butir & 0,779 & 0,60 & Reliable \\
PrestasiKerja & 5 butir & 0,752 & 0,60 & Reliable \\
\hline
\end{tabular}

Dari tabel di atas terlihat seluruh instrument berdasarkan analisis reliabilitas atas variabel penelitian menunjukkan bahwa nilai Cronbanch's alpha untuk semua variabel adalah diatas 0,6. Untuk itu seluruh variabel bisa dikatakan reliable (dapat diterima).

\section{Uji Tcr (Tingkat Capaian Responden)}

Persentase Total Capaian Responden Jawaban Indikator kualitas kerja

Responden (TCR) untuk item pertanyaan kualitaskerjaadalah sebesar $77 \%$ dengan kriteria cukup baik. Dapat disimpulkan bahwa kualitas kerja di PT. Laras Inter Nusa (LIN) Sidodadi Kinali Pasaman Barat. harus selalu diperhatikan oleh pimpinan agar terciptanya kinerja yang baik demi tercapainya tujuan perusahaan.

Persentase Total Capaian Responden Jawaban Indikator kompensasi

Responden (TCR) untuk item pertanyaan kompensasiadalah sebesar 84\% dengan kriteria baik. Dapat disimpulkan bahwa kompensasi di PT. Laras Inter Nusa (LIN) Sidodadi Kinali Pasaman Baratharus selalu diperhatikan oleh pimpinan agar terciptanya kinerja yang baik demi tercapainya tujuan perusahan.

\section{Persentase Total Capaian Responden Jawaban Indikator prestasi kerja} karyawan

Responden (TCR) untuk item pertanyaanprestasi kerja karyawan adalah sebesar $85 \%$ dengan kriteria baik. Dan diperhatikan oleh pimpinan PT. Laras Inter Nusa (LIN) Sidodadi Kinali Pasaman Barat ,agar terciptanya kinerja yang baik demi tercapainya tujuan perusahaan. 


\section{Uji Asumsi Klasik \\ 1.UjiNormalitas}

Tabel 6

HasilUjiNormalitas

\section{One-Sample Kolmogorov-Smirnov Test}

\begin{tabular}{|c|c|c|}
\hline & & izedResidual \\
\hline $\mathrm{N}$ & & \\
\hline Normal Parameters & Mean & 0 \\
\hline Normal Parameters & Std. Deviation & 0,98019606 \\
\hline & Absolute & 0,111 \\
\hline Most Extreme Differences & Positive & 0,111 \\
\hline & Negative & $-0,095$ \\
\hline Kolmogorov-Smirnov Z & & 0,798 \\
\hline Asymp. Sig. (2-tailed) & & 0,548 \\
\hline
\end{tabular}

2. Uji Multikolinearitas

Mendeteksi ada atau tidaknya multikolinearitas dapat dilihat dari nilai Tolerance dan Variance Inflation Factor (VIF). Nilai tolerance yang umum dipakai adalah $>0,10$ atau sama dengan nilai VIF $<10$ yang menandakan tidak terjadinya multikolinearitas.

Berdasarkan pengujian multikolinearitas dilakukan uji data terhadapa 52 responden dapat dilihat pada table dibawah ini :

Tabel 7

HasilUjiMultikolinearitas

\begin{tabular}{llrll}
\hline No & Variabel & Tolerance & VIF & Keterangan \\
\hline & KualitasKerja & 0,371 & 2,694 & TidakTerjadiMultikolinearitas \\
& Kompensasi & 0,371 & 2,694 & TidakTerjadiMultikolinearitas \\
\hline
\end{tabular}

Berdasarkan hasil uji multikolinearitas diatas menunjukkan bahwa semua variabel independen (kualitas kerjadan Kompensasi) mempunyai nilai tolerance besar dari 0,1 dan nilai VIF yang cukup kecil, dimana semuanya berada dibawah 10. Dengan demikian berdasarkan hasil uji multikolinearitas diatas dapat disimpulkan bahwa data variabel kualitas kerjadanKompensasi tidak terjadi hubungan multikolinearitas

\section{Uji Heteroskedastisitas}

\section{Tabel 8}

HasilUjiHeteroskedastesitas

\begin{tabular}{lllll}
\hline No & Variabel & Sig & Alpha & Keterangan \\
\hline 1 & KualitasKerja & 0,648 & 0,05 & Tidak Heteroskedastisitas \\
2 & Kompensasi & 0,399 & 0,05 & Tidak Heteroskedastisitas
\end{tabular}

Berdasarkan hasil uji heteroskedastisitas diatas, dapat diperoleh nilai signifikan dari variable Kualitas Kerja (X1) dan Kompensasi (X2) tidak terjadi heteroskedastisitas, karena nilai signifikan dari semua variable lebih besar dari tingkat signifikan yang digunakan $(\alpha=0,05)$. Dengan demikian 
dapat disimpulkan bahwa data hasil penelitian tidak mengalami kasus heteroskedastisitas.

\section{AnalisisRegresi Linier Berganda}

Tabel 9

Hasil Uji Analisis Regresi Linear Berganda

Coefficients $^{\text {a }}$

\begin{tabular}{lccccc}
\hline \multicolumn{1}{c}{ Unstandardized Coefficients } & \multicolumn{2}{l}{ Standardized } \\
\multicolumn{1}{c}{ Coefficients } \\
Model & \multicolumn{1}{c}{$\begin{array}{c}\text { Std. } \\
\text { Error }\end{array}$} & Beta & t & Sig. \\
\hline (Constant) & 1.100 & 1.460 & .753 & .455 \\
Kualitas & .779 & .113 & .7506 .865 & .000 \\
Kerja & .156 & .105 & .1631 .487 & .143 \\
Kompensasi & & & & & \\
\hline
\end{tabular}

a. Dependent Variable: Prestasi Kerja

Berdasarkan tabel diatas maka dapat dilihat persamaan regresinya yaitu :

$$
\mathrm{Y}=1.100+0,779 \mathrm{X} 1+0.156 \mathrm{X} 2+\mathrm{e}
$$

Nilai konstanta sebesar 1.100 berarti bahwa nilai Prestasi Kerja adalah sebesar 1,100dengan asumsi variabel lain bernilai nol.Nilai+ koefisien regresi Kualitas Kerja sebesar 0,779 maksudnya adalahsetiap peningkatan satu satuan Kualitas Kerja, maka akan mengakibatkan peningkatan nilai koefisien Prestasi Kerja sebesar 77,9\%. Dalam hal ini faktor-faktor lain yang mempengaruhi PrestasiKerja dianggap tetap.

Nilai koefisien regresi kompensasisebesar 0,156 maksudnya adalahsetiap peningkatan satu satuan Kompensasi, maka akan mengakibatkan penurunan nilai koefisien Presasi kerja sebesar 15,6\%. Dalam hal ini faktorfaktor lain yang mempengaruhi PrestasiKerja dianggap tetap.

\section{Uji Hipotesis}

1. Uji T

\section{Tabel 10}

Hasil Uji Parsial (Uji T)

Coefficients $^{\mathrm{a}}$

\begin{tabular}{lcrrrr}
\hline & \multicolumn{2}{c}{$\begin{array}{l}\text { Unstandardized } \\
\text { Coefficients }\end{array}$} & \multicolumn{3}{c}{$\begin{array}{c}\text { Standardized } \\
\text { Coefficients }\end{array}$} \\
Model & \multicolumn{1}{c}{ B } & Std. Error & Beta & t & Sig. \\
\hline $1 \quad$ (Constant) & 1.100 & 1.460 & & .753 & 455 \\
$\quad \begin{array}{l}\text { Kualitas } \\
\text { Kerja }\end{array}$ & .779 & .113 & .750 & 6.865 & .000 \\
\multicolumn{1}{l}{ Kompensasi } & .156 & .105 & .163 & 1.487 & .143 \\
\hline
\end{tabular}

a. Dependent Variable: Prestasi Kerja

Berdasarkan hasil uji t pada tabel 4.14 dapat dilakukan analisa sebagai berikut:

a. Kualitas kerja

Variabel Kualitas Kerja memilik $\mathrm{T}$ hitung 6.865 dengan nilai signifikan sebesar 0.000. yang berarti $\mathrm{T}$ hitung $(6.865)<$ dari $\mathrm{T}$ tabel $(2.032)$. Nilai 
signifikan sebesar 0.000 berarti kecildari taraf signifikan (0.05) yang berarti bahwa kualitaskerjaberpengaruh signifikan terhadap PrestasiKerjaKaryawan pada PT. Laras Inter Nusa (LIN) SidodadiKecamatanKinaliPasaman Barat. Hasil uji ini berarti menerima H1 yang mengatakan bahwa Kualitaskerja berpengaruh positif dan signifikan terhadap PrestasiKerjaKaryawan.

b. Kompensasi

Variabel Kompensasi memiliki $\mathrm{T}$ hitung 1.487 dengan nilai signifikan sebesar 0.143. dapat disimpulkan bahwa T hitung (1.487) < T tabel (2.032). Nilai signifikan sebesar 0.143 berarti besar dari taraf signifikan (0.05) yang berarti bahwa kompensasi berpengaruhpositif dan signifikan terhadap PrestasiKerja Karyawan padapada PT. Laras Inter Nusa (LIN) Sidodadi Kinali KecamatanPasaman Barat. Hasil uji ini berarti menerima H2 yang mengatakan bahwa Kompensasitidak berpengaruh positif dan signifikan terhadap PrestasiKerja Karyawan.

2. Uji Simultan (Uji F)

Tabel 11

Hasil Uji Simultan (Uji F)

ANOVA $^{\mathrm{b}}$

\begin{tabular}{lrrcrr}
\hline Model & Sum of Squares & Df & Mean Square & F & Sig. \\
\hline 1 Regressio & 283.404 & 2 & 141.70288 .256 & $000^{\mathrm{a}}$ \\
$\mathrm{n}$ & 78.673 & 49 & 1.606 & \\
Residual & 362.077 & 51 & & & \\
Total & & & & \\
\hline
\end{tabular}

a. Predictors: (Constant), Kompensasi, Kualitas Kerja

b. Dependent Variable: Prestasi Kerja

Dari tabel 4.15 diketahui hasil uji $\mathrm{F}$ sebesar 88,256 dan nilai signifikan $\mathrm{F}$ untuk variabel kualitas kerja dankompensasi sebesar 0,000 . Hal ini berarti signifikan F lebih kecildari taraf signifikan $(0,05)$. Hal ini menunjukkan ada pengaruh signifikan antara kualitas kerja dan kompensasi terhadap prestasi kerja karyawan pada PT. Laras Inter Nusa (LIN) Sidodadi Kinali KecamatanPasaman Barat.

\section{Uji Determinasi (R2)}

Tabel 12

Hasil Uji Determinasi (UJI R2)

Model Summary

\begin{tabular}{|c|c|c|c|c|}
\hline Model & $\mathrm{R}$ & $\begin{array}{l}\mathrm{R} \\
\text { Square }\end{array}$ & $\begin{array}{l}\text { Adjusted } \\
\text { R Square }\end{array}$ & $\begin{array}{l}\text { Std. Error of the } \\
\text { Estimate }\end{array}$ \\
\hline 1 & $885^{\circ}$ & 83 & .774 & 1.26711 \\
\hline
\end{tabular}

a. Predictors: (Constant), Kompensasi,

Kualitas Kerja

Berdasarkan table Diatas uji determinasi yang dilihat dari Adjusted $\mathrm{R}$ Square bernilai 0.774 , ini berarti bahwa $77,4 \%$ prestasi kerja karyawan dipengaruhi oleh kualitas kerja dan kompensasi. Selebihnya 22,6\% prestasikerjakaryawandipengaruhiolehvariabel lain seperti seleksi, rekrutmen, dan Penempatan kerja 


\section{SIMPULAN}

Berdasarkan hasil analisis dan pembahasan hasil pengujian hipotesis maka dapat diajukan sejumlah hasil yang merupakan jawaban dari masalah yang diajukan didalam penelitian ini yaitu:

1. Berdasarkan hasil pengujian $\mathrm{H} 1$ dengan mengunakan uji T statistik ditemukan bahwa variabel Kualitas Kerja memiliki nilai signifikan $(0.000>$ taraf signifikan $(0,05)$, dan nilai $\mathrm{t}$ hitung $(6.865)<\mathrm{t}$ tabel (2.032). Maka dapat dikatakan bahwa Kualitas Kerja berpengaruh positif d signifikan terhadap Prestasi Kerja Karyawan padapada PT. Laras Inter Nusa (LIN) Sidodadi Kinali Pasaman Barat.

2 Berdasarkan hasil pengujian $\mathrm{H} 2$ dengan mengunakan uji $\mathrm{T}$ statistik ditemukan bahwa variabel Kompensasi memiliki nilai signifikan sebesar (0.143) yang berarti besar dari taraf signifikan (0.05) dan nilai $t$ hitung (1.487) $<\mathrm{t}$ tabel (2.032). Sehingga dapat dikatakan bahwa Kompensasi berpengaruh positif dan signifikan terhadap Prestasi Kerja Karyawanpada PT. Laras Inter Nusa (LIN) Sidodadi Kinali Pasaman Barat.

\section{UCAPAN TERIMA KASIH}

Selesainya penulisan ini karena penulis banyak menerima masukan dan dorongan baik motivasi secara moral atau spiritual. Oleh karena itu penulis ingin mengucapkan terima kasih kepada Bapak Ahmad Yusri,SH sebagai manajer di PT. Laras Inter Nusa (LIN) Sidodadi Kinali Pasaman Barat yang telah menerima saya untuk melakukan penelitian dan Ibu Febsri Susanti SEI,MM sebagai dosen pembimbing dalam pembuatan skripsi. Dan penulis berharap kebaikan ibu bisa dibalas oleh Tuhan Yang Maha Esa. Selanjutnya terima kasih juga kepada seluruh bagian yang sudah banyak memberikan masukan yang tidak dapat penulis sampaikan satu persatu.

\section{DAFTAR PUSTAKA}

Ayu, D. G., \& Mayliza, R. (2019). Pengaruh Budaya Organisasi, Kompensasi Non Finansial, Dan Job Insecurity Terhadap Turnover Intention Pada PT. BPR Cincin Permata Andalas Cabang Padang. https://doi.org/10.31219/osf.io/nd8ta

Ghozali. (2005). Pengaruh Kompensasi dan Motivasi Kerja terhadap Kinerja Karyawan pada PT . Devina Surabaya, 5, 94.

Ghozali. (2011). Analisis Kinerja Karyawan ditinjau dari Kompensasi dan Motivasi Kerja Sebagai Variabel Intervining pada pg. Soedhono ngawi (vol. 8).

Gomez. (2009). Akbar Rizky Adhani; Pengaruh Kebutuhan Aktualisasi Diri 2003, $1,153$.

Indrianto. (2006). Metode Penelitian Bisnis Untuk Akuntansi dan Manajemen.

Martinus. (2016). pengaruh kmpensasi dan motivasi terhadap kinerja karyawan 
dengan kepuasaan kerja sebagai variabel intervening.

Mayliza, R. (2019). Pengaruh Kompensasi Finansial, Lingkungan Kerja Dan Motivasi Kerja Terhadap Kinerja Pegawai Pada Kantor PDAM Kota Payakumbuh. https://doi.org/10.17605/OSF.IO/DZXAF

Rasimin. (1987). Pengaruh Keselamatan dan Kesehatan Kerja terhadap Prestasi Kerja Karyawan pada PT . Pln ( PERSERO ) apj semarang.

Simamora. (2004). Kinerja Karyawan di Broadway barbershop pt bersama lima putera, 5(1).

Sudjana. (2003). Pengaruh Motivasi, Pengawasan Dan Disiplin Kerja Terhadap Prestasi Kerja Pegawai Dinas Pendapatan, Pengelola Keuangan Dan Kekayaan Daerah Kabupaten Tapanuli Tengah, 1(1).

Sugiyono. (2002). Statistik Untuk Penelitian.

Sugiyono. (2008). Metode Penelitian Bisnis. bandung: Alfabeta.

Sugiyono. (2009). Metode Penelitian Bisnis.

Sugiyono. (2012). Memahami Penelitian Kualitatif. bandung.

Sugiyono, P. D. (2017). metode penelitian bisnis (edisi 3). bandung.

Wilson\&Heyel. (1987). Pelatihan, Disiplin kerja dan Kualitas Kerja Terhadap Prestasi Kerja pada PT. PLN (PERSERO) Area Manado. 1987, 2(2). 